\title{
Editorial
}

Respiration

Respiration 2006;73:143-144

DOI: $10.1159 / 000091529$

\section{Inspiratory Muscle Training: A Way to Breathe More Easily}

\author{
Enrico Clini Stefania Costi
}

Department of Pulmonary Rehabilitation, Fondazione Villa Pineta and University of Modena, Pavullo, Italy

Inspiratory muscles have been specifically targeted for training patients with chronic obstructive pulmonary disease (COPD). So far, the rationale for training has been questioned.

Although inspiratory muscle strength is low in most of these patients, mainly because of the mechanical disadvantage due to hyperinflation, respiratory muscles are likely to adapt to the chronically imposed work of breathing [1], and the diaphragmatic contractile fatigue is rarely observed even during strenuous exercise in stable disease [2]. On the one hand, respiratory muscles, unlike the peripheral muscles, apparently do not to suffer from deconditioning, and a training intervention does not appear justified on this basis. On the other hand, the work of the diaphragm is clearly increased during exercise [3], thus leading to perception of 'difficult inspiration', 'shallow breathing' or 'unrewarded inspiration' [4], especially in some COPD patients whose respiratory muscle adaptation may be insufficient.

Therefore, if inspiratory muscle training (IMT) is able to increase the maximal inspiratory muscle pressure $\left(\mathrm{PI}_{\max }\right)$, and to change the structure of these muscles, it seems reasonable to expect that symptoms will be reduced while exercising, thus turning these effects into a functional benefit. These positive effects have been confirmed in COPD patients with inspiratory muscle weakness by a recent systematic review [5].

\section{KARGER}

Fax +4161306 1234

E-Mail karger@karger.ch

www.karger.com
(C) 2006 S. Karger AG, Basel

$0025-7931 / 06 / 0732-0143 \$ 23.50 / 0$

Accessible online at: www.karger.com/res
IMT programs require regular supervision but are relatively inexpensive and can be conducted at home. One study investigating the long-term effect of IMT suggested that benefits wear off rapidly when training is discontinued [6]. Whether training conducted with appropriate load also translates into increased exercise tolerance and better quality of life is still unclear, thus making the evidence-based guidelines $[7,8]$ to conclude that IMT should not be a routine component in the rehabilitation programs.

In this issue of Respiration, Weiner et al. [9] pointed out a practical problem in the management of COPD patients showing weakness of their inspiratory muscles. This may cause, in turn, the inability to generate adequate flow to assure lung deposition when using dry powder inhalers (DPIs), which are commonly prescribed to deliver bronchodilators to these patients. Bioavailability is predictive of the clinical effect of the inhaled drug [10] and peak inspiratory flow (PIF) measurements reflect the patient's ability to properly inhale the drug.

Authors have found that almost $20 \%$ of the most compromised patients (staged according to the forced expiratory volume in $1 \mathrm{~s}$ ) are not able to generate enough flow to assure proper inhalation (and therefore deposition) from one of the most popular and commonly used devices (Turbohaler) and that, in addition, PIF values cor- 
relate with a patient's $\mathrm{PI}_{\max }$ [9]. Since the maximal inspiratory flow, at a given volume, depends both on airway resistance and on strength as well as the speed of shortening of the inspiratory muscles [11], it is reasonable that IMT should enable those COPD patients with respiratory muscle weakness to assure adequate drug deposition in their lungs and, therefore, bronchodilation. Indeed, Weiner et al. [9] have demonstrated that IMT at adequate load significantly increased PI $\mathrm{Imax}_{\text {and }}$ PIF in weak COPD patients.
This problem, outside a clinical trial, may involve about one third of COPD patients [12], i.e. these subjects are unlikely to benefit from most part of the drug delivered by means of DPIs at home. Finally, the experience gained by Weiner et al. [9] shows that training inspiratory muscles allows patients to use any type of DPI and suggests that 'the systematic measurement of PIF and $P I_{\text {max }}$ ' in the most compromised COPD patients may warrant a proper way to improve breathing and consequently drug inhalation.

\section{References}

1 Levine S, Kaiser L, Leferovich J, Tikunov B: Cellular adaptations in the diaphragm in chronic obstructive pulmonary disease. $\mathrm{N}$ Engl J Med 1997;337:1799-1806.

2 Mador MJ, Kufel TJ, Pineda LA, Sharma GK: Diaphragmatic fatigue and high-intensity exercise in patients with chronic obstructive pulmonary disease. Am J Respir Crit Care Med 2000;161:118-123.

3 Sinderby C, Spahija J, Beck J, Kaminski D, Yan S, Comtois N, Sliwinski P: Diaphragm activation during exercise in chronic obstructive pulmonary disease. Am J Respir Crit Care Med 2001;163:1637-1641.

4 O'Donnell DE, Bertley JC, Chau LK, Webb KA: Qualitative aspects of exertional breathlessness in chronic airflow limitation: pathophysiologic mechanisms. Am J Respir Crit Care Med 1997;155:109-115.
5 Lotters F, Van Tol B, Kwakkel G, Gosselink $\mathrm{R}$ : Effects of controlled inspiratory muscle training in patients with COPD: a meta-analysis. Eur Respir J 2002;20:570-576.

6 Weiner P, Magadle R, Beckerman M, Weiner $\mathrm{M}$, Berar-Yanay N: Maintenance of inspiratory muscle training in COPD patients: one year follow-up. Eur Respir J 2004;23:61-65.

7 ACCP/AACVPR evidence-based guidelines. ACCP/AACVPR Pulmonary Rehabilitation Guidelines Panel. American College of Chest Physicians. American Association of Cardiovascular and Pulmonary Rehabilitation. Chest 1997;112:1363-1396.

8 British Thoracic Society. Pulmonary rehabilitation. Thorax 2001;56:827-834.

9 Weiner P, Weiner M: Inspiratory muscle training may increase peak inspiratory flow in chronic obstructive pulmonary disease. Respiration 2006;73:151-156.
10 Derom E, Borgstrom L, Van Schoor J, Lofroos AB, Pauwels R: Lung deposition and protective effect of terbutaline delivered from pressurized metered-dose inhalers and the Turbuhaler in asthmatic individuals. Am J Respir Crit Care Med 2001;164:1398-1402.

11 Fry DL, Hyatt RE: Pulmonary mechanics: a unified analysis of the relationship between pressure, volume and gas flow in the lungs of normal and diseased human subjects. Am J Med 1960;29:672-689.

12 De Boer AH, Winter HMI, Lerk CF: Inhalation characteristics and their effects on in vitro drug delivery from dry powder inhalers. 1. Inhalation characteristics, work of breathing and volunteer's preference in dependence of the inhaler resistance. Int J Pharm 1996;130:231244. 